DIW BERLIN

Discussion

Papers

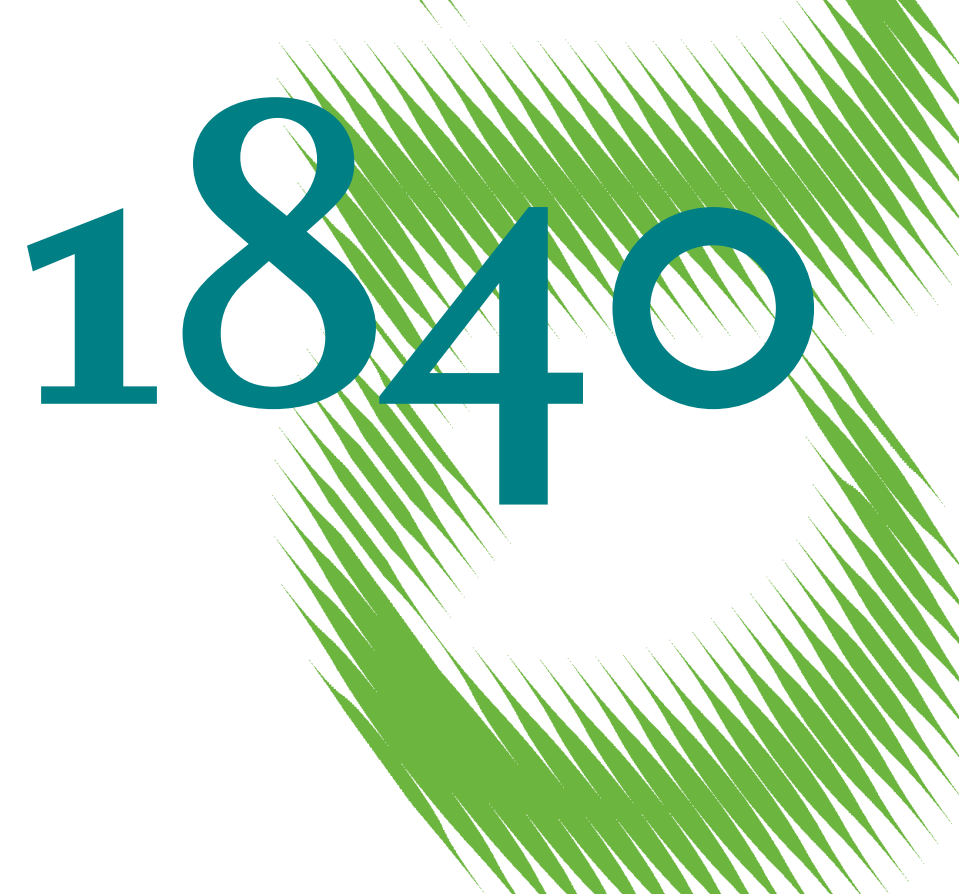

The Role of Aggregators in

Facilitating Industrial Demand Response Evidence from Germany 
Opinions expressed in this paper are those of the author(s) and do not necessarily reflect views of the institute.

IMPRESSUM

(C) DIW Berlin, 2020

DIW Berlin

German Institute for Economic Research

Mohrenstr. 58

10117 Berlin

Tel. +49 (30) $89789-0$

Fax +49 (30) $89789-200$

http://www.diw.de

ISSN electronic edition 1619-4535

Papers can be downloaded free of charge from the DIW Berlin website:

http://www.diw.de/discussionpapers

Discussion Papers of DIW Berlin are indexed in RePEc and SSRN:

http://ideas.repec.org/s/diw/diwwpp.html

http://www.ssrn.com/link/DIW-Berlin-German-Inst-Econ-Res.html 


\title{
The role of aggregators in facilitating industrial demand response: Evidence from Germany
}

\author{
Jan Stede ${ }^{\mathrm{a}^{*}}$, Karin Arnold ${ }^{\mathrm{b}}$, Christa Dufter ${ }^{\mathrm{c}}$, Georg Holtz ${ }^{\mathrm{b}}$, Serafin von Roon ${ }^{\mathrm{c}}$, \\ Jörn C. Richstein ${ }^{a}$
}

\begin{abstract}
Industrial demand response can play an important part in balancing the intermittent production from a growing share of renewable energies in electricity markets. This paper analyses the role of aggregators - intermediaries between participants and the electricity market - in facilitating industrial demand response. Based on the results from semi-structured interviews with German demand response aggregators, as well as a wider stakeholder online survey, we examine the role of aggregators in overcoming barriers to industrial demand response. We find that a central role for aggregators is to raise awareness for the potentials of demand response, as well as to support implementation by engaging key actors in industrial companies. Moreover, we develop a taxonomy that helps analyse how the different functional roles of aggregators create economic value. We find that there is considerable heterogeneity in the kind of services that aggregators offer, many of which do create significant economic value. However, some of the functional roles that aggregators currently fill may become obsolete once market barriers to demand response are reduced or knowledge on demand response becomes more diffused.
\end{abstract}

Keywords: Aggregator, demand response, barriers, function, roles, industry, interview JEL codes: D22, L23, Q40, Q41

\footnotetext{
${ }^{*}$ Corresponding author.

${ }^{a}$ German Institute for Economic Research (DIW Berlin), Climate Policy Department, Mohrenstr. 58, 10117 Berlin, Germany.

${ }^{\mathrm{b}}$ Wuppertal Institute for Climate, Environment and Energy, Döppersberg 19, 42103 Wuppertal, Germany.

${ }^{\mathrm{c}}$ Research Center for Energy Economics (FfE), Am Blütenanger 71, 80995 Munich, Germany.

Email addresses: jstede@diw.de (J. Stede), karinar@wupperinst.org (K. Arnold), cdufter@ffe.de (C. Dufter), georg.holtz@wupperinst.org (G. Holtz), sroon@ffe.de (S. von Roon), jrichstein@diw.de (J. Richstein)
} 


\section{Introduction}

In many countries, the electricity system is currently undergoing substantial changes. The continuously growing share of renewable energies leads to an increase in the number of generation units, while installed capacity per unit decreases. Second, the volatility of electricity generation rises and the traditional paradigm of generation following load is no longer valid. Consequently, a flexible (intentionally responsive) demand side - so-called demand response - gains importance as an effective measure to maintain grid stability and reduce the need for costly grid expansions or backup generation capacity (Strbac, 2008; Eid et al., 2016).

Generally, demand response means that electricity consumers change their consumption in response to external signals. These signals can be either price signals from the day-ahead or intraday market, or direct signals from the transmission system operator to activate balancing power (see e.g. EC, 2013; Ikäheimo et al., 2010; SEDC, 2015). Suppliers of demand response typically offer units that are smaller than traditional generators, and their active participation in electricity markets marks a new territory for many electricity market stakeholders. A large share of the cost-effective demand response potential lies in industry (Gils, 2014).

These developments lead to the evolvement of a new actor - the demand response aggregator Different definitions of aggregators exist. In general, aggregators can market both supply side and demand-side units, acting as intermediaries between distributed energy resources (demand response, distributed generation and energy storage) and the power markets. The aggregated pool can be utilised as a single resource, similar to a large conventional power plant. Burger et al. (2017, p. 396) define aggregation as "[...] the act of grouping distinct agents in a power system (i.e. consumers, producers, prosumers, or any mix thereof) to act as a single entity when engaging in power system markets (both wholesale and retail) or selling services to the system operator(s)".

The focus of this paper is the facilitation of industrial demand response. Therefore, we restrict our analysis to aggregators that market at least some demand response units. This leads to the following definition of demand response aggregators:

An aggregator pools distributed units and markets their generation capacity (generation plants) or demand-side flexibility (electricity consumers) on the spot market, balancing power market and possibly further markets. For this

purpose, the aggregator provides recommendations (or control signals) for the units' generation or load profile.

Demand response aggregators are aggregators that (also) market demand-side flexibility.

This paper studies to what extent demand response aggregators help overcome barriers to industrial demand response. A second focus of the paper is to analyse the activities through which aggregators create long-run economic value. We do so by developing hypotheses regarding functional roles (activities) of aggregators and testing these hypotheses by conducting semistructured interviews with demand response aggregators, as well as an online survey with different electricity market participants and other stakeholders. We focus on the German market, since Germany is a major industrialised country that has seen a rapidly increasing share of renewable electricity in recent years (Fraunhofer ISE, 2019). The interviews and the survey help to understand how demand response aggregators facilitate industrial demand response. 
In a next step, we derive a taxonomy mapping six different functional roles that aggregators can assume to a framework of economic value creation by aggregators developed by Burger et al. (2017). We use the taxonomy to evaluate the economic values created by the aggregation of demand response. Finally, we discuss which of the economic value created by the aggregators' functional roles can also be captured by regulatory changes to the market design. Thus, we examine the role of demand response aggregators in today's electricity markets, as well as how this role may evolve in the future.

The paper is structured as follows. We give a brief introduction to the possible electricity markets for demand response in Germany and discuss the literature on demand response and its barriers in Section 2. In Section 3 we describe our methodology, develop hypotheses regarding functional roles and describe our empirical findings from the aggregator interviews, as well as the online survey. Section 4 discusses these findings, and links them to categories of value creation. Section 5 gives policy recommendation and concludes.

\section{Industrial demand response, electricity markets and barriers}

\subsection{Overview of German electricity markets and reserves}

The German wholesale electricity market is organised as a so-called energy-only market (EOM). ${ }^{1}$ An EOM only remunerates the electricity that is generated, unlike a capacity market, which provides explicit incentives to invest in electricity generation capacities (or demand response). To secure grid stability, the EOM in Germany is supplemented by the balancing energy market and other ancillary services (such as cold start capabilities, voltage control etc.). Furthermore, to guarantee security of supply, there are additional reserves that have not been competitively tendered, which compensate capacities from power plants that have been temporarily shut down, are in cold reserve or are merely on standby.

Electricity is traded on the EOM either in over-the-counter trading, based on bilateral agreements based on various types of products, or on the electricity exchange. The spot market of the electricity exchange consists of two markets. First, on the day-ahead market trading takes place within auctions with an hourly resolution until the day before delivery. On the intraday market, electricity can be traded until five minutes before delivery at the latest. In principle, participation to the EOM is open to all actors, and minimum trading volumes are fairly low ( $0.1 \mathrm{MW}$ on the dayahead market). However, balancing responsibility in Germany is organised in portfolios, so-called balancing groups ("Bilanzkreise"), which are managed by a balance responsible party (BRP). These actors - often the electricity supplier of a consumer - are responsible for keeping the schedule in balance via matching of production and consumption of all their participating parties and by trading and netting foreseeable imbalances. Balance responsible parties bear imbalance costs for any imbalances resulting from short-term deviations from the schedule. As a result, unless

\footnotetext{
${ }^{1}$ The basis for the market design is the act on the further development of the electricity market („Gesetz zur Weiterentwicklung des Strommarktes (Strommarktgesetz) $)^{\circ}$ ) of 2016, which can be accessed at https://www.bgbl.de/ (in German).
} 
consumers are BRPs themselves ${ }^{2}$, the cooperation of the BRP is needed in order to participate in wholesale electricity markets.

The control power market comprises three types of reserves: the primary control (PRL), the secondary control (SRL) and the minute reserve (MRL), which vary in terms of their activation time until full power must be provided (30s/5 min/15 min), the provision time ( $\max .15 \mathrm{~min} / \mathrm{up}$ to $1 \mathrm{~h} / 15 \mathrm{~min}$ up to several hours), and various requirements for the bidders such as minimum bid sizes (1 MW/5 MW/5 MW), type of activation (automatic/automatic/manual) and availability requirements. ${ }^{3}$ Participation in these reserve markets is limited based on technical criteria. In order to be licensed to provide balancing power, the provider must first undergo a prequalification procedure, in which the suitability of the proposed technical unit (or pool of units) is inspected and tested. For the PRL only a capacity price is paid, i.e. the remuneration is based on the capacity held available. The remuneration of the SRL and the MRL includes both a capacity price component and an energy-related component. Similarly, to the EOM market, cooperation by the BRP is needed to offer flexibility in the control reserves; however, BRPs are obliged by regulation to enable participation in these reserves (StromNZV \$26a).

In the context of flexible industrial processes, the directive on switchable loads $(\mathrm{AbLaV})^{4}$ is also relevant. Loads contracted under $\mathrm{AbLaV}$ can be switched off by the transmission grid operator on very short notification periods in the event of grid congestion in order to reduce the load. ${ }^{5}$ As with control power, the loads are contracted through tenders issued by the transmission grid operators.

\subsection{Potential for industrial demand response in Germany}

A number of bottom-up studies have estimated that there is a significant potential for demand response in the German industry. A major share lies in the energy-intensive industries, such as aluminium, steel, cement, paper and the chemical industry. Most studies focus on technical potentials, hence neglecting practical and economic aspects. Moreover, flexibility potentials are differentiated between industrial processes and cross-sectional technologies, such as compressed air, lighting, heating and cooling.

For Germany, technical load reduction potentials in the range of $2 \mathrm{GW}$ to $3 \mathrm{GW}$ have been found for production processes in the energy-intensive industry. Potentials for load increase are smaller, ranging between $0.3 \mathrm{GW}$ and $1.3 \mathrm{GW}$ (see e.g. Klobasa, 2007; Paulus and Borggrefe, 2011; Langrock et al., 2015; Gruber, 2017; Steurer, 2017). Estimated potentials differ due to different methods and assumptions (Dufter et al., 2017; Müller and Möst, 2018). The literature on crosssectional technologies, on the other hand, is rather scarce, although corresponding demand response potentials are not negligible. Depending on the time of activation, potentials for load reduction vary between 1.2 GW (one hour of activation) and 0.6 GW (several hours of activation). Again, potentials for load increase are smaller, ranging between $1 \mathrm{GW}$ (one hour) and $0.2 \mathrm{MW}$ (four hours, see Gruber, 2017; Steurer, 2017). Gils (2014) finds demand response potentials for

\footnotetext{
${ }^{2}$ Large industrial consumers, for example, sometimes manage their own balancing group.

${ }^{3}$ www.regelleistung.net.

4 "Verordnung über Vereinbarung zu abschaltbaren Lasten". https://www.gesetze-im-internet.de/ablav_2016/

5 There are two categories, 350 milliseconds and 15 minutes.
} 
processes and cross-sectional technologies of $4.4 \mathrm{GW}$ and $0.8 \mathrm{GW}$ for load reduction and load increase, respectively. ${ }^{6}$

In sum, load reduction potentials of approximately 3 to $4.4 \mathrm{GW}$ can be assumed for processes and cross-sectional technologies in the German industry. This equals to a demand response potential of 3.8 per cent to 5.5 per cent of peak load in Germany that could be realised in the short term. ${ }^{7}$ This is in line with a review of the potentials for industrial demand response in several Northern European countries by Söder et al. (2018), who find load reduction potentials of 4.7 per cent - 7.1 per cent of peak load. Note that the actual economic potential of demand response is smaller than the technical potential. The economic potential may vary over time with the system need for flexibility, as well as market and system service prices.

\subsection{Barriers for industrial demand response}

Electricity customers are traditionally used to a constant supply with electricity, which makes demand inelastic (Torriti et al., 2010). While not all technical potential of demand response can be economically leveraged, additional hurdles to exploit the economic potential of demand response exist. Barriers to economic industrial demand response can broadly be categorised into barriers at the firm level (behavioural and/or organisational), informational barriers and barriers related to the market design (or regulatory environment). ${ }^{8}$

On the firm level, the priority of industrial firms is to maintain a good relation with their customers. This means that product quality may not suffer due to demand response and delivery periods must be kept. Consequently, load shedding is typically not an option in industry, but the focus is on shifting demand from one point in time to another (Arnold et al., 2018). Moreover, an important behavioural barrier in the context of demand response is the issue of trust between the provider of demand response (firm) and the buyer (e.g. demand response aggregator, see Good et al., 2017). The issue of trust has several dimensions. Most importantly, industrial clients may be reluctant to share the control of their production processes with another company. Additionally, firms may also be worried to pass on sensitive data. Finally, consumers (both firms and individuals) may be characterised by inertia (reluctance to change behaviour or adapt organisational structures) and bounded rationality (settling for the "good enough"; see Kim and Shcherbakova, 2011; Good et al., 2017). This means that firms may not engage in demand response, although it would increase their profits.

Regarding informational barriers, one central problem of including demand response as a resource similar to a generator according to the literature is the difficulty of calculating a baseline consumption (Nolan and O'Malley, 2015). This baseline is needed in order to remunerate deviations from the consumption profile that was originally planned. Moreover, ICT infrastructure needs to be installed in order to use units in demand response programmes. This technical equipment is costly (Eid et al., 2016). Third, there are transaction costs associated with collecting and processing demand response market information (Good et al., 2017).

\footnotetext{
${ }^{6}$ Considering that technical barriers are disregarded, the potentials appear rather small compared to the studies listed above.

${ }^{7}$ Peak load equals approximately $80 \mathrm{GW}$ in Germany (ÜNB, 2018a).

${ }^{8}$ For a comprehensive review of barriers, see O’Connell et al. (2014) and Good et al. (2017).
} 
There are a number of barriers to industrial demand response related to market design. First, there are often no rules that (implicitly) consider demand response participation in the provision of different services. In other words, appropriate market structures are missing (Cappers et al., 2013; Koliou et al., 2014). This is a problem in the EU, where there are no homogeneous demand response products over different European countries (Paterakis et al., 2017). To explicitly define the role of an aggregator in providing energy services by demand response is especially important when retailer and balance responsible party are two different entities (Vallés et al., 2016). ${ }^{9}$ There are also explicit barriers to market entry such as minimum bid size to participate in balancing markets (Paterakis et al., 2017).

Second, network tariffs can have an important effect on the incentives for demand response (Vallés et al., 2016). As Perez-Arriaga et. al. (2017) point out, yearly peak demand-related charges (fixed charges) may have detrimental effects. The reason is that deviation from a flat demand profile is penalised, as Richstein and Hosseinioun (2019) confirm in a simulation study. This reduces the revenues that can be achieved for flexibility and makes demand response financially less attractive. In Germany, there are explicit disincentives for demand response due to exemptions from the network tariffs regulation that hinge on high full-load hours demand profiles. ${ }^{10}$ Third, on the spot markets (day-ahead and intraday), the level and volatility of electricity prices determine the profitability of demand response. Uncertainty on the number and the duration of high-price periods due to possible changes in the future regulatory environment are an obstacle to investments in demand response (Ländner et al., 2019). This holds for both wholesale markets, as well as control power markets.

\section{Methodology and empirical findings}

\subsection{Methodology}

We use a mix of different qualitative methods (Creswell and Plano Clark, 2011) to answer our research questions on the functional roles of aggregators and the barriers to industrial demand response that can be overcome by aggregators. In a first step, we developed hypotheses on the functional roles of aggregators. We also carried out a desktop research to identify key stakeholders for our subsequent empirical case study consisting of interviews, an online survey and a stakeholder workshop.

Second, we carried out semi-structured interviews with German demand response aggregators in order to identify the type of economic value aggregators create. We conducted a series of five interviews with aggregators covering a major share of total demand response portfolio of all

\footnotetext{
${ }^{9}$ In Germany, units that want to offer flexibility on the balancing power markets had to come to an agreement with the balance responsible party to keep the balance with all other participants until the year 2017. Due du a legislative change in Germany in 2017, balancing responsible parties are now obliged to grant third-party aggregators access to the balancing power markets ( $\iint$ 26a, 27 Abs. 1 Nr. 23 StromNZV, operationalized by Az. BK6-17-046, BNetzA). However, no obligation to provide third-party access to intraday markets exists.

$10 \$ 19$ StromNEV par. 2 on agreed individual (reduced) grid utilisation fees was originally designed to incentivise grid utilisation in off-peak hours. However, when a firm deviates from its usual load pattern due to demand response, the change in the demand profile may result in high penalties that can hardly be compensated by higher revenues from demand response.
} 
German aggregators. In order to identify the relevant players, a desk research was carried out in order to identify all German aggregators that market demand response (Table A-1 in the Appendix). Next, the 12 aggregators we identified were contacted to identify their portfolio size. Five interviewees representing more than half of the combined portfolio size marketed by all German aggregators were available for an interview. The interviews lasted $1.5-2 \mathrm{~h}$ each and were either held in person or by telephone between July and December 2018. The goal was to test the hypotheses we developed, and adapt them where necessary. Moreover, the interviews provided valuable insights in the business models of the different aggregators, such as the kind of markets they serve.

Third, the results of the interviews were discussed in a one-day stakeholder workshop among a broader group of experts consisting of aggregators, as well as stakeholders from industry, utilities, network operators and research. The workshop was complemented by an online survey, using a questionnaire with half-open questions. The survey was sent in advance to participants of the stakeholder workshop with 20 participants, which was held at DIW Berlin on 14 April 2019. 15 of the 20 participants of the workshop (75 per cent) took part in the survey, including representatives from three aggregators, four firms that market some of their flexible demand, three network operators, three researchers and consultants, one energy utility and one power exchange.

In a fourth and final step, we develop a taxonomy linking the functional roles of aggregators to the creation of different types of economic value, building on the findings from our interviews and the survey. The taxonomy maps different roles of aggregators that facilitate industrial demand response to different types of economic value created by aggregators (see Burger et al., 2017). The taxonomy is discussed in Section 4.

\subsection{Hypotheses on the functional roles of aggregators}

There is a long history of the literature on the roles of aggregators (or retailers ${ }^{11}$ ) and the value they bring to the electricity market, starting with the discussions between Joskow (2000) and Littlechild (2000) on whether retailer competition is expected to bring economic benefits to electricity markets. Whereas Joskow argued that little is to gain from retail competition, and a regulated pass-through of wholesale prices to consumers would entail lower costs, Littlechild argues that retailers have important roles to play in price formation (especially for forward markets), and in terms of providing value-added services.

Updating the debate to current conditions in electricity markets, Burger et al. (2017) give an overview of the related literature on the value that aggregators (may) provide and identify three categories of economic values. The first group consists of fundamental benefits of aggregation, which leads to efficiency improvements in the system, regardless of market structure and regulatory imperfections. The second group of economic values comprises transitory benefits that may resolve over time with market or technological development. Finally, the last group encompasses the opportunistic value of aggregation, resulting from imperfections of market design.

\footnotetext{
${ }^{11}$ Retailers have been ascribed a more active role (similar to the one of aggregators) in earlier literature.
} 
We develop a set of functional roles that demand response aggregators may fulfil in the process of marketing demand-side resources. ${ }^{12}$ These (hypothesized) roles were used in the development of the semi-structured questionnaire for the interviews with aggregators. Building on the results of these interviews (Section 3.3), we finally develop a taxonomy in Section 4 that maps the set of aggregator roles to the categories of economic values developed by Burger et al. (2017). In the following, the hypothesised functional roles of demand response aggregators are shortly described:

\section{Identification of flexibility potentials}

This functional role concerns the identification of flexibility potentials in industrial companies. The hypothesis is that aggregators may help companies identify potentials for demand response flexibility within their organisation.

\section{Realisation of flexibility potentials}

This functional role concerns the realisation of flexibility potentials, that is, all activities between the identification of the potential and the first activation and marketing of the resource. This may be installation of ICT infrastructure, (support of) prequalification procedures for reserve power markets, staff training etc.

\section{Automation}

This role concerns the automation of providing flexibility measures. In this paper, we define automation as the automated activation of flexibility options at the industrial site, and not as automated trading. Automation may simply entail sending the customer control signals, but it may also include a fully automated and integrated resource planning, which optimises production under consideration of electricity costs and revenues from providing electricity services. The role of automation may be closely interlinked to the role of participation in electricity market.

\section{Participation in electricity markets, services \& provision of related information}

This function comprises the participation in electricity markets and services by the aggregator on behalf of its customers, as well as the provision of related information (such as prices) to companies. It is often implemented through an automated control of demand-side resources, but could in principle be performed separately (depending on the market structure and regulatory environment).

\section{Provision of risk management products \& suitable contracts for companies}

Aggregators may also provide risk management products, as well as suitable contracts for industrial companies. This may either be standardised contracts traded on exchanges, or non-standardised contracts tailored to companies, where a residual risk remains with the aggregator. There is a certain overlap to the business model of retailers, where the demand response aggregator is also the energy provider of the industrial client.

\footnotetext{
${ }^{12}$ Note that these roles need not necessarily be fulfilled by aggregators, but other actors may also perform the same functions.
} 


\section{Bundling of services}

Aggregators may bundle several services and offer those combined services to their clients. These different services could be the participation in several types of electricity markets, but also the cooptimisation of electricity with other energy markets.

The next section discusses empirical findings from the aggregator interviews, as well as the online survey. A ranking of the relative importance of the different functional roles is given in section 3.3.7.

\subsection{The functional roles of aggregators: Empirical findings}

\subsubsection{Identification of demand-side flexibility}

The interviews showed that when marketing demand-side flexibility in Germany, the first impulse for the identification of potentials typically comes from the aggregator. In other words, aggregators pro-actively search for and contact new customers, while the reverse seems to be the exception. In doing so, aggregators help to overcome the barrier of companies' inertia to engage with the topic. If aggregators cannot access existing customers from other industries or want to contact additional customers, the industry sector is a first criterion for the selection of the companies to be contacted. The reason is that, based on their understanding of production processes and technologies, aggregators typically have expectations regarding the flexibility potential of companies in a given industrial sector.

There was no consensus among interviewed aggregators if learning takes place, i.e. whether the knowledge gained on the identification of typical demand response potentials can be transferred to the identification of potentials in other companies within a sector. However, aggregators agreed that the identification of the actual potentials of a company is usually not a big hurdle due to the wide diffusion of energy management systems among industrial customers. Energy management systems simplify the identification of potentials, since all industrial processes with their capacities and energy requirements are already recorded.

Both the interviews and the responses to the questionnaire showed that for an exact determination of potentials that go beyond those of standard processes, a cooperation between the aggregator (knowledge of electricity markets) and the company (knowledge of technical facilities) is necessary. Moreover, the interviews revealed that for the identification of flexibility potentials, the different requirements of the electricity markets and the control power markets (see Section 2.1) are decisive. For participation in the control power markets, for example, the short-term controllability of the processes, the ability to perform defined gradients as well as a suitable continuity in the availability of the load are central in order to fulfil the prequalification conditions. The requirements for participation in the electricity markets are lower. Here, however, participation is only worthwhile if a certain amount of energy can be marketed - with any associated effects on the production processes (see Section 2.3).

\subsubsection{Realisation of potentials}

The aggregator interviews revealed the central importance of the aggregator's role of helping to realise demand response potentials. One major result is that the hurdles for the realisation of 
flexibility potentials are often organisational rather than technical. A main challenge stressed during the interviews is that demand-side flexibility (or sophisticated energy procurement) is typically not reflected in the organisation of (potential) customers. ${ }^{13}$ The aggregators saw this as the biggest challenge for the realisation of flexibility potentials. ${ }^{14}$

A large part of the aggregator's work therefore consists of triggering a "change process": Finding the right contact person in the company and convincing them to consider offering demand response. This process includes establishing a first contact within the company with electricity buyers, followed by the energy manager, the technical production manager, and finally management. The interviews revealed that in this process, building trust with a future client is of central importance, and that this process may take several years. For many services, the aggregator has to be granted (automated) control of processes. Offering demand-side flexibility in core production processes in particular therefore requires good previous experience with automation in peripheral plants. By helping to put the topic of demand side flexibility on the agenda of companies, aggregators contribute to addressing the barrier of a low priority of demand-side flexibility.

The online survey confirmed the major importance of the functional role of realising demand response potentials. Respondents rated this activity as the most important role of aggregators (see section 3.3.7). It includes infrastructure development, support for "change processes", as well as support for prequalification processes. In addition, the survey also showed that most respondents perceived aggregators as an important support in the installation of the ICT infrastructure that is required for marketing of flexibility.

The barrier of a lack of a client's trust to grant the aggregator access to sensitive data of the industrial site, on the other hand, was not confirmed to constitute a major barrier in the online questionnaire. Several respondents mentioned that non-disclosure agreements are a typical solution to this issue.

\subsubsection{Automation}

The required degree and depth of automation of an activation of flexibility depends on the market where the flexibility is offered. For primary control, secondary control and ABLaV, an automatic activation of flexibility (of the pool offered by the aggregator) by the transmission system operator (TSO) is mandatory. Within the aggregator's pool of dispatchable resources, an automated control of the individual technical units by the aggregator is required for these products.

From a technical point of view, a fully automated control of the client's technical units by the aggregator is typically not a problem. However, the industrial company always has the option (depending on the operating status of the plant) of either (automated) vetoing the activation of flexibility for slower products or declaring a non-availability of units ex-ante. In the event of a veto or deviation by the industrial company, the aggregator must provide back-up capacity to ensure that the flexibility promised to the TSO can be provided.

\footnotetext{
${ }^{13}$ An exception are large companies and power-intensive industries, which often deal with this issue due to their high electricity costs already.

${ }^{14}$ One reason given for this was that the expected revenues from marketing flexibility are currently very low in Germany.
} 
For participation in the minute reserve and the electricity markets, the level of automation differs between the different aggregators we interviewed. In these markets, direct access by the aggregator to individual technical units of the industrial company is not (legally) required. In these cases, it may be sufficient that the aggregator provides recommendations for the operation of a unit, and the company decides whether to implement these recommendations.

\subsubsection{Participation in electricity markets}

Aggregators help to overcome market entry barriers by allowing industrial loads to participate in markets that would otherwise be closed to them. Examples of such markets include the reserve markets, which require a minimum bid size and back-up capacity (see Section 2.1). However, some aggregators reported that they also have clients that are large enough to engage in all electricity markets themselves, but choose to work with a demand response aggregator. One reason for this is a reduction of costs for participating in markets such as the certified ICT infrastructure in the balancing markets, which aggregators reported to be a costly hurdle for industrial companies. ${ }^{15}$ Many of the aggregators we interviewed provide the ICT infrastructure to the client without a fee as part of their service.

As discussed, automation and participation in electricity markets are tightly interlinked. Aggregators take different approaches of trading on spot markets associated with different automation needs. These approaches range from simple threshold strategies to complex models that optimise the use of a pool across different markets. Some aggregators only provide market information, leaving the use of this information to their clients. On the other hand, one of the aggregators interviewed uses a complex optimisation model, which is used to trade continuously in the intraday market on a 24hour basis, requiring automated call-offs. Here, automation saves substantial resources, since companies would need a 24-hour trading desk to participate in these markets without automated call-offs. Again, the industrial company may always decide to deviate from the schedule provided by the aggregator, thus retaining control of their production processes.

Aggregators thus help to overcome barriers constituted by transaction costs associated with market participation. Another important role of aggregation towards this end is the reduction of the need for backup capacity. This is especially relevant in the case of balancing markets, where there are strict requirements for availability. It is much more costly to fulfil these requirements for an individual industrial company, than for a pool of different loads. ${ }^{16}$ Therefore, all the aggregators we interviewed rely on a pool of demand-side resources to reliably deliver demand response by providing redundant capacity when they are selling capacity on the balancing markets.

Again, not all barriers named in the literature seem to be relevant in the context of industrial demand response in Germany. Regarding participation, the difficulty of calculating a baseline consumption was not confirmed to constitute a barrier for the cooperation between aggregators and their customers in the interviews. The reason is that balancing responsible parties need to report schedules to the TSO, and are thus already reliant on reports from industrial customers regarding their projected (baseline) consumption.

\footnotetext{
15 Balancing power is seen as "critical infrastructure" (KRITIS) in Germany, and is therefore subject to stricter (more costly) regulation with respect to the security of the IT infrastructure (ÜNB, 2018b).

${ }^{16}$ On the German balancing markets, generation or load can only be marketed according to the "N-1"-criterion. This means that out of a pool of resources prequalified for the balancing markets, all but one units can actually be marketed, such that there is back-up capacity in case one of the units does not deliver. In the absence of an aggregator, a company with two flexible units would have to withhold one of them, leading to much higher costs. In a larger pool of an aggregator (large $\mathrm{N}$ ), on the other hand, the costs of withholding one unit are relatively much smaller.
} 


\subsubsection{Provision of hedging}

The responses to the online questionnaire showed that uncertainty about future price developments and regulatory changes constitute a barrier to industrial firms' engagement with flexibility issues. However, the potentials of aggregators to overcome this barrier are seen as low, as those issues are beyond the control of the aggregator.

In the interviews, aggregators reported major differences between the types of contracts offered to their clients. On the one extreme, risks and revenues are shared between aggregator and client. On the other hand, some aggregators offer a certain insurance against short-term spot market price risks, for example by guaranteeing minimum revenues from selling flexibility. In some cases, risk management products are also offered for longer time horizons. The aggregator typically asks for an additional premium for these risk management products. For some clients, risk hedging is even more important than the extra revenues from a marketing of flexibility.

When the aggregator is also the energy supplier of its client, it may offer an integrated package of a hedging product (fixed prices of electricity supply), as well as potential revenues from a marketing of demand response. Generally, the more risks the aggregator takes on, the more important it becomes to have a high level of control over the client's production processes.

\subsubsection{Bundling of services}

The aggregators we interviewed serve a very different set of markets, ranging from only primary control reserve, to a range of electricity and gas markets. While some are only active in marketing the ancillary service balancing power, others focus on the intraday and day-ahead markets. These different activities have implications on the view of whether an aggregator should also be the balance responsible party (BRP), as well as the electricity supplier for its client. Larger industrial companies often manage their own balancing group, and for aggregators only active in the balancing power markets there is no need to be either balance responsible party or supplier. For aggregators with a broader market scope, on the other hand, an integrated role (aggregator, BRP and supplier) is vital, since it guarantees access to the intraday and day-ahead markets and allows for an integrated optimisation of electricity market activity and the costs for balancing energy. ${ }^{17}$

One major advantage of bundling several services to a client, for example by combining the roles of energy retailer and aggregator marketing industrial demand response, is the reduction of acquisition costs. Since engaging potential customers to market industrial load is a major challenge (see section 3.3.2), reducing acquisition costs by building on trust established in an existing business relationship may be of significant value to the aggregator. Additionally, an integrated portfolio management of electricity and gas markets may also lead to efficiency gains, especially for companies also owning (gas) generation units, or running processes with possible hybrid operation modes.

\subsubsection{Ranking of the importance of the different aggregator roles}

Building on the interviews, we assess the relative importance of the functions we hypothesized aggregators may fulfil to facilitate demand response. To this end, we used the online survey carried out among participants of the stakeholder workshop (discussed in Section 3.1) in order to get a

\footnotetext{
${ }^{17}$ The European Commission has recognised the importance of market access for the demand side. In its 2016 "Winter Package", it calls for a "non-discriminatory access" of the demand side to "all organised markets", including demand response offered through aggregators (EC 2016).
} 
sense how stakeholders from industry, network operators and research value the relative importance of these different functional roles.

Figure 1 graphs the relative importance of the six different functional roles. Participants of the survey were asked to name the three most important roles of aggregators to facilitate demand response. Respondents could choose one of the six roles we hypothesized, or come up with different roles. From these answers, for each role an average rank is calculated, which ranges from a theoretical value of three (if all of the respondents choose that specific role as the most important one) to zero (if none of the respondents names the role).

The realisation of flexible demand resources emerged as the most important function of aggregators (average rank of 1.8), followed by allowing small loads to participate in electricity markets (e.g. in reserve markets) and providing related information (average of 1.3). Consequently, this confirms that processes of organisational change in order to realise and market potentials that are theoretically available are a major function that aggregators perform. Moreover, hurdles to the participation in electricity markets such as minimum size requirements in reserve markets are also an important barrier that is overcome by aggregation. Interestingly, the identification of processes suitable for demand response was considered as less important (average rank of 0.9). This is in line with the result from the aggregator interviews that identification of flexible demand resources within companies is typically not a major hurdle (Section 3.3.1). Moreover, risk management was deemed to be only of minor importance.

Figure 1: Relative importance of the different functional roles of aggregators according to survey participants

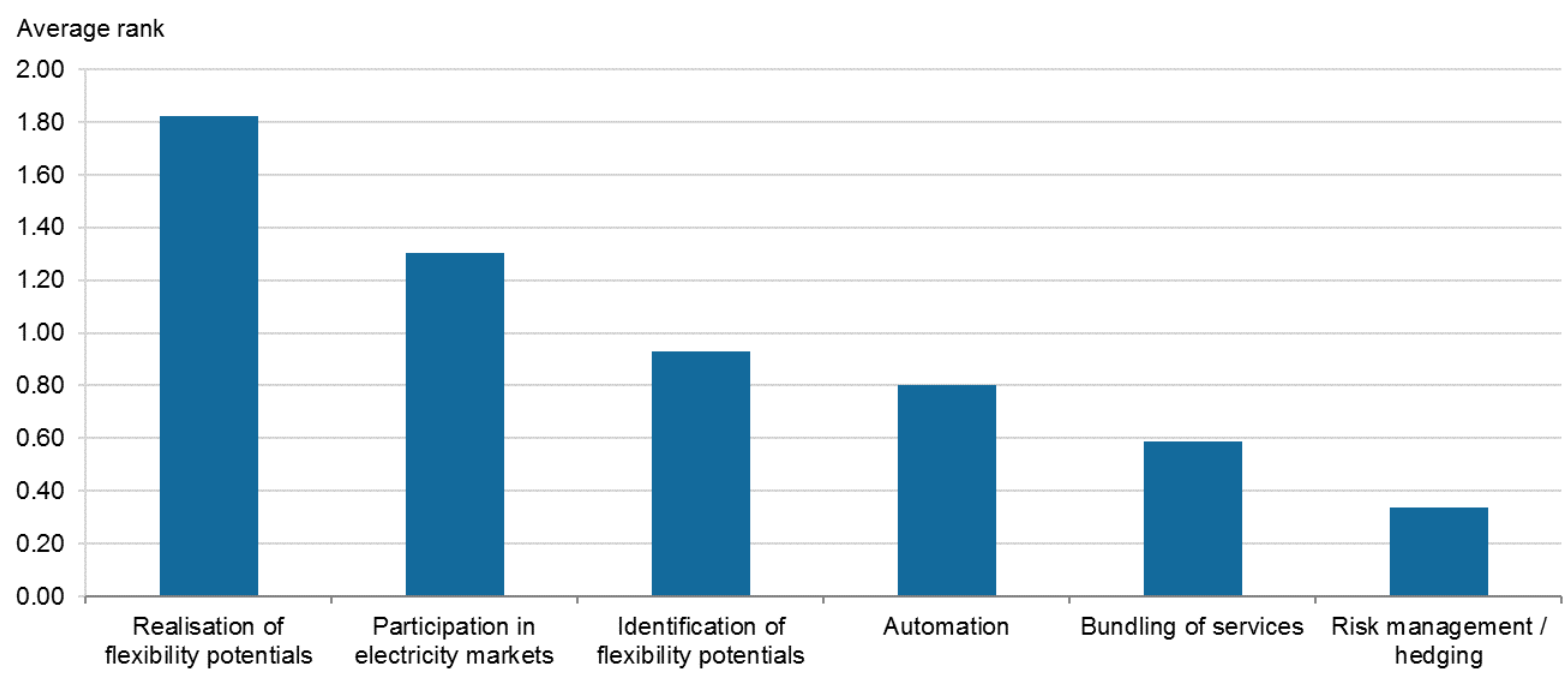

Notes: For the calculation of average ranks, we assign the values three to one to the functional roles of aggregators that have been named as the most important ones (rank one to three) for every respondent. For every role, we then compute the average rank over all respondents (correcting for multiple answers). The maximum value a role could have is three, which would result if all respondents chose the same role as the most important one.

\section{Taxonomy and discussion: Economic values of functional roles, and their dependence on market design}

Although there is considerable heterogeneity in the kind of services that aggregators offer, the functional roles we developed were confirmed as relevant in the interviews. In a next step, we 
develop a taxonomy that maps aggregator roles to the value categories developed by Burger et al. (2017), introduced in Section 3.2 (see Table 1 for the subcategories). The goal of the taxonomy is to analyse how aggregators create economic value. Specifically, we discuss whether the functional roles of aggregators are central to their business model, and whether they will remain to be important under an evolving market design. Functional roles that predominantly provide fundamental value will probably also be central to the business model of aggregators in the future. Transitory values, on the other hand, may become less important as the market for demand response matures. Finally, value derived from regulatory imperfections may cede to be of economic value if the regulatory framework is developed further.

The drivers for fundamental value creation are economies of scale and scope, managing uncertainty and price risks and increased competition and potential for innovation (both business and technical) by heterogeneous market actors (Burger et al., 2017). On the other hand, the closing of market information gaps, engaging distributed agents in electricity markets, as well as automation and coordination issues with TSOs and exchanges are only of transitory value. These activities may lose importance if market design improves and behaviours and technologies favouring demand response are widely adopted in the market. Finally, Burger et al. identify several regulatory imperfections (such as group balance responsibility, penalties for non-provision of reserves), which favour the use of aggregators without creating fundamental economic value.

Table 1 maps the discussed functional roles to the value categories, based on the discussion in the previous section. It becomes clear that nearly all functional roles bring some fundamental benefits, and are additionally either of transitory value, opportunistic value, or both. 
Table 1: Taxonomy of functional roles of aggregators and economic value creation

\begin{tabular}{|c|c|c|c|c|c|c|c|c|}
\hline \multirow{2}{*}{$\begin{array}{l}\text { Values } \\
\\
\text { Functional Role }\end{array}$} & \multicolumn{4}{|c|}{ Fundamental } & \multicolumn{3}{|c|}{ Transitory } & \multirow[t]{2}{*}{ Opportunistic } \\
\hline & 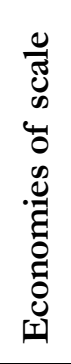 & 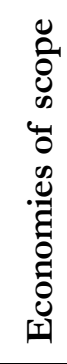 & 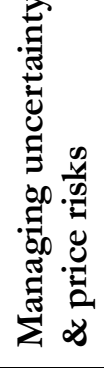 & 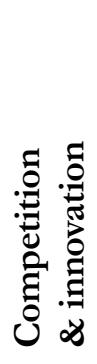 & 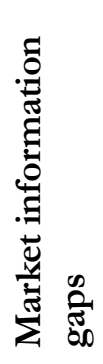 & 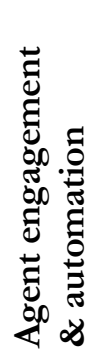 & 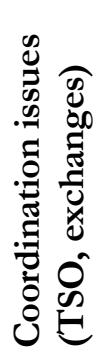 & \\
\hline $\begin{array}{l}\text { Identification of } \\
\text { flexibility potentials }\end{array}$ & (x) & (x) & & & $\mathrm{x}$ & $\mathrm{x}$ & & \\
\hline $\begin{array}{l}\text { Realisation of flexibility } \\
\text { potentials }\end{array}$ & $\mathrm{x}$ & & & $\mathrm{x}$ & & $\mathrm{x}$ & $\mathrm{x}$ & \\
\hline Automation & $\mathrm{x}$ & $\mathrm{x}$ & & $\mathrm{x}$ & & $\mathrm{x}$ & & \\
\hline $\begin{array}{l}\text { Participation in } \\
\text { electricity markets \& } \\
\text { provision of information }\end{array}$ & $\mathrm{x}$ & $\mathrm{x}$ & & & $\mathrm{x}$ & $\mathrm{x}$ & $\mathrm{x}$ & $\mathrm{x}$ \\
\hline $\begin{array}{l}\text { Provision of risk } \\
\text { management products \& } \\
\text { suitable contracts }\end{array}$ & $\mathrm{x}$ & & $\mathrm{x}$ & $\mathrm{x}$ & $\mathrm{x}$ & & $\mathrm{x}$ & \\
\hline Bundle several services & & $\mathrm{x}$ & & $(\mathrm{x})$ & & & $\mathrm{x}$ & $\mathrm{x}$ \\
\hline
\end{tabular}

Source: Own elaboration, matching functional roles of aggregators to the categories of value creation developed by Burger et al. (2017).

\subsubsection{Identification of demand-side flexibility}

On the one hand, this function is important in terms of agent engagement, as previously nonactive parties on the power market may become aware via aggregators of the (potential) opportunities of demand-side flexibility. Moreover, industrial companies can benefit from aggregators' know-how on electricity markets. This is an important role, but may prove transitory if demand response becomes more prevalent, e.g. due to higher price volatility on electricity markets. Within the interviews, there were conflicting views on whether experience gained in identifying flexibility potentials can be transferred within and across industries (see Section 3.3.1). It is therefore unclear whether there are significant economies of scale and scope via aggregators for this functional role. Possible reasons that these may not exist is the uniqueness of large industrial processes.

\subsubsection{Realisation of potentials}

For realisation of flexibility potentials, the interviews revealed that the major value added by aggregators is also agent engagement. Interviewees named the lack of a suitable organisation structure and set-up to realise demand response as a major hurdle (cf. Section 3.3.2) - as demand response gets more profitable and diffused, this hurdle may be reduced and prove to be transitory. 
Second, aggregators may solve coordination issues with TSOs (and to a lesser degree power exchanges). Examples include the pre-qualification of units, as well as the establishment of certified ICT infrastructure. While this work entails some economies of scale (as pre-qualification procedures and establishing ICT infrastructure are similar over different companies), there is partly a transitory value to it. The reason is that the issue of coordination depends on regulation, as well as the currently limited know-how of companies. Finally, realisation entails some fundamental value connected to innovation and competition regarding ICT infrastructures and business models. Aggregators may compete on technical and organisational innovations. Moreover, there are economies of scale for the installation of ICT infrastructure, such as standardised energy boxes (cf. Burger et al., 2017).

\subsubsection{Automation}

Automating demand response processes offers several fundamental values, such as economies of scale and scope due to the aggregation of consumers on fewer, larger ICT systems. There are larger economies in the case of central aggregation as opposed to having many aggregators (Burger et al., 2017). Differing automation solutions may also lead to increased competition and innovation between aggregators, in this case with benefits from having many aggregators. The fact that aggregators typically provide free ICT infrastructure to their clients (Section 3.3.3) reduces transaction cost for the customer.

Part of the value of increased automation that aggregators may bring is in terms of agent engagement, since aggregators are well equipped to spread the knowledge and practice of automating flexibility provision from industrial processes. However, this value is transitory since the interviews revealed that, from a technical point of view, a fully automated control of the client's technical units by the aggregator is typically not a problem. In the long run, therefore, automation may be performed by industry itself.

\subsubsection{Participation in electricity markets}

The interviews revealed that, although some of the aggregators' clients would in principle be large enough to participate in electricity markets themselves, these companies nevertheless choose to employ the services of an aggregator (cf. Section 3.3.4). One explanation for this behaviour is that participation in electricity markets via aggregators may result in the creation of fundamental value via economies of scale and scope. Reasons for the existence of economies of scale are fixed costs for ICT (for trading), the fulfilment of regulatory requirements and necessary staff (e.g. a 24-hour trading desk for intraday trading). There are also economies of scope, since many of the different electricity markets rely on similar equipment and personnel (see discussion in the section on bundling). In principle, however, this form of aggregation could also be done on a higher level, e.g. by the network operator or power exchanges, who could provide easier access to electricity markets via lower size thresholds or more bidding formats that can reflect the physical properties of demand response units. In other words, a player other than an aggregator could theoretically also fulfil this role.

Our interviews show that aggregators close information gaps by exposing companies to price signals they were not exposed to before. Some aggregators provide simple market information; others go as far as fully automated trading on behalf of their client. With a developing regulatory framework this benefit will be reduced. Aggregators also reduce coordination issues and friction 
with TSOs and market exchanges by coordinating information exchanges between different market actors (cf. Burger et al., 2017).

In addition to these transitory benefits, part of the value aggregators capture is due to regulatory shortcomings: Limits to market participation by size, penalties on top of marginal costs for failure to perform, balancing responsibilities, as well as the absence of locational price signals all favour large portfolios rather than individual participation in electricity markets, without increasing the efficiency of the market.

\subsubsection{Provision of hedging}

The provision of hedging in principle can provide economic value if providers of industrial demand response are risk averse. Hedging provides an efficient means to distribute risks to those willing to bear it or those that have complementary hedging needs, for example inflexible demand that would like to be protected against price peaks. However, suitable hedging products for demand response are not sufficiently standardised or liquidly traded, so market actors may provide new innovative products to hedge demand response (Littlechild, 2000). Burger et al. (2017) argue that aggregators can "act as intermediaries between small consumers/producers and volatile markets [and] provide hedging solution to market players", thus filling information gaps and resolving coordination issues between market exchanges and many small players. ${ }^{18}$ Moreover, larger portfolios allow for pooling of risks, thus resulting in economies of scale.

In our interviews and the online survey, on the other hand, several participants doubted whether risk management is a role an aggregator has to fill. In the online survey, several participants stated that they do not consider risk hedging a fundamental activity of an aggregator. Additionally, some of the aggregators we interviewed do not provide any risk management products for their clients.

There may be several reasons why this role is currently not fulfilled by all aggregators. The possibility to offer risk-management products hinges on whether the aggregator has sufficient capital. The fact that there were several acquisitions of aggregators active in the German market by bigger players with a larger capital base (see Appendix) may mean that more of these players will be able to offer risk management products in the future. Furthermore, currently industrial demand response is mainly provided by overcapacities of current installations. If investment decisions in overcapacities to provide demand response take place, these may have a stronger need to be hedged.

\subsubsection{Bundling of services}

Bundling several roles, for example combining the roles of energy retailer and aggregator, may lead to the creation of significant fundamental value. The aggregator interviews showed that building trust with customers is difficult and takes several years, i.e. acquisition and transaction costs are high. This leads to economies of scope at the acquisition stage, e.g. when a retailer with longrunning relationship to its client offers additional aggregator services. Further economies of scope may exist at the operation stage, especially if opportunity costs need to be explicitly considered between different energy/electricity markets. This is the case in Germany, where co-optimisation

${ }^{18}$ Littlechild (2000) already discussed that the improved design of suitable long-term and hedging contracts are an advantage of deregulated retail markets, resulting from increased competition. 
between energy and reserves is not done by the system operator. Bundling services across several markets and industries may also open up the space for further product and service innovation (Burger et al., 2017). There is also some transitory value for the coordination of activities, which may in the future be captured by the system operator (e.g. co-optimisation of energy and reserves).

\section{Conclusion and policy recommendations}

Fundamental changes in electricity markets are leading to a growing importance of utilising (industrial) demand response potentials. Aggregators serve as intermediaries between load and the electricity market, and have therefore received increasing attention in recent years. This paper investigates how demand response aggregators may overcome barriers to industrial demand response and facilitate the realisation of demand response potentials by bringing them to the market. We develop a set of functional roles that aggregators take up in the market, and investigate which of the different aggregator activities create economic value based on a set of interviews with German demand response aggregators, as well as a survey of market participants and further stakeholders.

We find that demand response aggregators fill six functional roles. Aggregators (1) identify flexibility potentials, and (2) help industrial companies realise them on their premises. Moreover, they (3) automate the activation of flexibility potentials, and (4) participate in electricity markets to market them. Finally, demand response aggregators may provide (5) hedging solutions to stabilise revenues from providing flexibility and (6) bundle several services across electricity and other (energy) markets.

Realising theoretical demand response potentials emerged as the single most important role that aggregators currently have in the German electricity market. One central finding from our interviews is that in Germany demand response aggregators typically approach potential clients (industrial loads) pro-actively and need to persuade companies of marketing flexibility, because demand-side flexibility is often not reflected in the organisation of industrial companies and thus no actor from within the company feels responsible for and has incentives to engage with this topic. Therefore, demand side aggregators play an important role in realising theoretical demand response potential and bringing them to the market. In this process, building trust with a future client - a costly "change process" characterised by high acquisition costs - is a major challenge for the aggregator.

Interestingly, some of the barriers named in the literature on barriers to demand response did not emerge as major hurdles in the context of industrial demand response in Germany. First, nondisclosure agreements typically resolve the issue of a lack of a client's trust to grant the aggregator access to sensitive data of the industrial site. Second, the identification of industrial processes that can be used for demand response is usually not a big hurdle due to the wide diffusion of energy management systems among industrial customers. Third, the estimation of a baseline electricity consumption was not a barrier in the context of industrial demand response, since a planned consumption profile has to be reported by industrial loads anyways. This preliminary profile can then serve as a baseline. 
With a growing prevalence of demand response, some of the value that aggregators create may prove transitory, as knowledge on how to identify, realise and automate demand response spreads. In the case of larger industrial loads, for example, clients may become more sophisticated at managing their energy costs in the future, if potential returns become higher due to an increased price volatility or higher price spikes on electricity markets. It is therefore not clear how important demand response aggregators will be in the future for these clients.

However, aggregators also create fundamental value by economies of scale and scope. Examples are providing certified ICT infrastructure for participation in the balancing markets to their clients and serving more consumers on fewer, larger ICT systems, serving different electricity markets with similar technical equipment, as well as saving their clients staff costs, such as for intraday trading. The ICT infrastructure required to participate in balancing markets, for example, is a major hurdle to demand response which aggregators help to overcome.

Aggregators may also create fundamental value by managing uncertainties, as well as increasing competition and innovation. Currently, only some of the German demand response aggregators we interviewed offer hedging products to their clients. The possibility to offer risk-management products hinges on whether the aggregator has sufficient capital. However, this role may become more important in the medium term, since the aggregator interviews showed that risk hedging is more important to some of the clients than the extra revenues from a marketing of flexibility. Currently, however, there is considerable heterogeneity in the kind of services that aggregators offer to their industrial clients.

There are several policy options to facilitate (industrial) demand response that would also render obsolete some of the roles that aggregators currently play. These include lowering size thresholds for participation in balancing markets, as well as introducing multi-part bids, which reflect the physical properties of demand response units. In the current regulatory framework, enabling companies to participate in electricity markets emerged as the second most important role of aggregators. However, changes in the market design that reduce access barriers, for example by providing a suitable intraday auction platform for industrial loads would reduce the need for aggregators to participate in these markets on behalf of their clients. It is therefore likely that aggregators will need to evolve as the relative importance of their different functional roles shifts with different market conditions and a changing regulatory environment. 


\section{Acknowledgements}

The authors are grateful for financial support from the German Federal Ministry of Education and Research under grant numbers 03SFK3S0, 03SFK3L0 and 03SFK3O0 (SynErgie project). The views and opinions expressed in this publication do not necessarily reflect the views of the Ministry.

We would also like to thank our interview partners, as well as the participants of the workshop on industrial demand response and the role of aggregators on 9 April 2019. We thank Karsten Neuhoff for helpful comments and suggestions. 


\section{References}

Arnold, K., Holtz, G., Dietrich, R.-U., Estelmann, S., 2018. Methode zur Ermittlung technischer, organisatorischer und regulatorischer Hemmnisse, in: Ausfelder, F., Seitz, A., von Roon, S. (Eds.), Flexibilitätsoptionen in der Grundstoffindustrie: Methodik, Potenziale, Hemmnisse. DECHEMA, Frankfurt am Main, pp. $24-30$.

Burger, S., Chaves-Ávila, J.P., Batlle, C., Pérez-Arriaga, I.J., 2017. A review of the value of aggregators in electricity systems. Renewable and Sustainable Energy Reviews 77, 395-405. doi:10.1016/j.rser.2017.04.014

Cappers, P., MacDonald, J., Goldman, C., Ma, O., 2013. An assessment of market and policy barriers for demand response providing ancillary services in US electricity markets. Energy Policy 62, 1031-1039. doi:10.1016/j.enpol.2013.08.003

Creswell, J.W., Plano Clark, V.L., 2011. Designing and Conducting Mixed Methods Research, 2nd ed. SAGE Publications, Inc, Thousand Oaks, CA.

Dufter, C., Guminski, A., Orthofer, C., von Roon, S., Gruber, A., 2017. Lastflexibilisierung in der Industrie - Metastudienanalyse zur Identifikation relevanter Aspekte bei der Potenzialermittlung. Presented at the IEWT 2017, München.

EC, 2013. Incorporing demand side flexibility, in particular demand response, in electricity markets. Commission Staff Working Document No. SWD(2013) 442 final.

Eid, C., Koliou, E., Valles, M., Reneses, J., Hakvoort, R., 2016. Time-based pricing and electricity demand response: Existing barriers and next steps. Utilities Policy 40, 15-25. doi:10.1016/j.jup.2016.04.001

Fraunhofer ISE, 2019. Annual renewable shares of electricity production in Germany. https://energy-charts.de/ren_share_de.htm?source=ren-share\&period=annual\&year=all (accessed 9.5.19).

Gils, H.C., 2014. Assessment of the theoretical demand response potential in Europe. Energy 67, 1-18. doi:10.1016/j.energy.2014.02.019

Good, N., Ellis, K.A., Mancarella, P., 2017. Review and classification of barriers and enablers of demand response in the smart grid. Renewable and Sustainable Energy Reviews 72, 57-72. doi:10.1016/j.rser.2017.01.043

Gruber, A.-M., 2017. Zeitlich und regional aufgelöstes industrielles Lastflexibilisierungspotenzial als Beitrag zur Integration Erneuerbarer Energien ( $\mathrm{hhD}$ Thesis). Technische Universität München.

Ikäheimo, J., Evens, C., Kärkkäinen, S., 2010. DER Aggregator business: the Finnish case. Technical Research Centre of Finland (VTT), Espoo, Finland.

Joskow, P.L., 2000. Why do we need electricity retailers? Or can you get it cheaper wholesale? (WP No. 00-001). CEEPR / Sloan School of Management at MIT, Cambridge, MA.

Kim, J.-H., Shcherbakova, A., 2011. Common failures of demand response. Energy 36, 873-880. doi:10.1016/j.energy.2010.12.027

Klobasa, M., 2007. Dynamische Simulation eines Lastmanagements und Integration von Windenergie in ein Elektrizitätsnetz auf Landesebene unter regelungstechnischen und Kostengesichtspunkten (PhD Thesis). ETH Zurich.

Koliou, E., Eid, C., Chaves-Ávila, J.P., Hakvoort, R.A., 2014. Demand response in liberalized electricity markets: Analysis of aggregated load participation in the German balancing mechanism. Energy 71, 245-254. doi:10.1016/j.energy.2014.04.067

Ländner, E.-M., Märtz, A., Schöpf, M., Weibelzahl, M., 2019. From energy legislation to investment determination: Shaping future electricity markets with different flexibility options. Energy Policy 129, 1100-1110. doi:10.1016/j.enpol.2019.02.012

Langrock, T., Achner, S., Jungbluth, C., Marambio, C., Michels, A., Weinhard, P., Baumgart, B., Otto, A., 2015. Potentiale regelbarer Lasten in einem Energieversorgungssystem mit wachsendem Anteil erneuerbarer Energien (Climate Change No. 19/2015). Umweltbundesamt. 
Littlechild, S.C., 2000. Why we need electricity retailers: A reply to Joskow on wholesale spot price pass-through (Working Paper No. 21/2000). Judge Institute for Management Studies, University of Cambridge, Cambridge, UK.

Müller, T., Möst, D., 2018. Demand Response Potential: Available when Needed? Energy Policy 115, 181-198. doi:10.1016/j.enpol.2017.12.025

Nolan, S., O'Malley, M., 2015. Challenges and barriers to demand response deployment and evaluation. Applied Energy 152, 1-10. doi:10.1016/j.apenergy.2015.04.083

O’Connell, N., Pinson, P., Madsen, H., O’Malley, M., 2014. Benefits and challenges of electrical demand response: A critical review. Renewable and Sustainable Energy Reviews 39, 686699.

Paterakis, N.G., Erdinç, O., Catalão, J.P.S., 2017. An overview of Demand Response: Key-elements and international experience. Renewable and Sustainable Energy Reviews 69, 871-891. doi:10.1016/j.rser.2016.11.167

Paulus, M., Borggrefe, F., 2011. The potential of demand-side management in energy-intensive industries for electricity markets in Germany. Applied Energy 88, 432-441. doi:10.1016/j.apenergy.2010.03.017

Pérez-Arriaga, I.J., Jenkins, J.D., Batlle, C., others, 2017. A regulatory framework for an evolving electricity sector: Highlights of the MIT utility of the future study. Economics of Energy \& Environmental Policy 6, 71-92. doi:10.5547/2160-5890.6.1.iper

Richstein, J., Hosseinioun, S.S., 2019. Industrial demand response: How network tariffs and regulation do (not) impact flexibility provision in electricity markets and reserves (DIW Discussion Papers No. (forthcoming)).

SEDC, 2015. Mapping demand response in Europe today. Smart Energy Demand Coalition, Brussels.

Söder, L., Lund, P.D., Koduvere, H., Bolkesjø, T.F., Rossebø, G.H., Rosenlund-Soysal, E., Skytte, K., Katz, J., Blumberga, D., 2018. A review of demand side flexibility potential in Northern Europe. Renewable and Sustainable Energy Reviews 91, 654-664. doi:10.1016/j.rser.2018.03.104

Steurer, M., 2017. Analyse von Demand Side Integration im Hinblick auf eine effiziente und umweltfreundliche Energieversorgung ( $\mathrm{PhD}$ Thesis). Institut für Energiewirtschaft und Rationelle Energieanwendung der Universität Stuttgart.

Strbac, G., 2008. Demand side management: Benefits and challenges. Energy Policy 36, 4419-4426. doi:10.1016/j.enpol.2008.09.030

Torriti, J., Hassan, M.G., Leach, M., 2010. Demand response experience in Europe: Policies, programmes and implementation. Energy 35, 1575-1583. doi:10.1016/j.energy.2009.05.021

ÜNB, 2018a. Bericht der deutschen Übertragungsnetzbetreiber zur Leistungsbilanz 2017-2021. Übertragungsnetzbetreiber.

ÜNB, 2018b. Mindestanforderungen an die Informationstechnik des Reservenanbieters zur Erbringung von Regelreserve. Übertragungsnetzbetreiber.

ÜNB, 2018c. Präqualifizierte Leistung in Deutschland. Übertragungsnetzbetreiber.

ÜNB, 2018d. Bericht der Übertragungsnetzbetreiber zu abschaltbaren Lasten gem. \ 8 Abs. 3 $\mathrm{AbLaV}$. Übertragungsnetzbetreiber.

Vallés, M., Reneses, J., Cossent, R., Frías, P., 2016. Regulatory and market barriers to the realization of demand response in electricity distribution networks: A European perspective. Electric Power Systems Research 140, 689-698. doi:10.1016/j.epsr.2016.04.026 


\section{Appendix}

\section{Market overview of aggregators in Germany and marketed demand response}

We identify 11 German aggregators that market demand response in Germany. We complemented our desk research by a question on demand response aggregators in the online survey, such that we are confident to have identified all major demand response aggregators active on the German market. There were several acquisitions of aggregators in Germany in recent years, such as Entelios (bought by EnerNOC) and REstore (acquired by Centrica). Table A-1 gives an overview of German demand response aggregators and the type of electricity markets and reserves they serve.

\section{[Table A-1 here]}

Table A-1 shows that the aggregators interviewed for this study represent a major share of the German aggregator market. We compare the portfolio size of the five demand response aggregators we interviewed to the total portfolio size of demand response and flexible generation marketed in Germany. We find that the five aggregators we interviewed have portfolios of 12.5 GW under management, which includes both generation and demand units. This translates to more than 50 per cent of the aggregate portfolio marketed by aggregators in Germany and gives confidence in the conclusions drawn from these interviews. ${ }^{19}$

Several other aspects become apparent when studying Table A-1. First, most demand response aggregators offer secondary and tertiary balancing power, as well as intraday optimization. Marketing via the directive on switchable loads (AbLaV) and day-ahead markets are less common. Second, most aggregators serve similar customers, with companies in the basic materials sector and energy-intensive industry the most relevant. ${ }^{20}$ Third, demand response aggregators were mostly founded relatively recently. The two exceptions Ørsted and MVV Energie are utilities, which later included demand response aggregation in their business model.

The portfolios of the five interviewed aggregators by far exceed the total amount of demand response prequalified for the reserve markets and for AbLaV. A total of $4.5 \mathrm{GW}$ of demand response were prequalified for the balancing power market (positive and negative) and $\mathrm{AbLaV}$ in 2018 (Table A-2). Since the same load may be prequalified for different services, the total prequalified demand response capacity is in the range of one GW (amount prequalified for $\mathrm{AbLaV}$ ) and $4.5 \mathrm{GW}$ (sum of balancing markets and AbLaV). Additional loads may be active on day-ahead and intraday markets. However, data on demand response from these markets is not available since bids are submitted anonymously.

There are two reasons why portfolios exceed the amount of prequalified demand response. First, aggregator portfolios include units used for optimization on intraday and day-ahead market, which are not necessarily prequalified for the balancing power markets. Second, the aggregators' portfolios not only include flexible demand, but also generation units. Unfortunately, the share of prequalified demand response by aggregator is not available. At least with respect to the combined

\footnotetext{
${ }^{19}$ For the aggregators were we do not have information on their portfolio size, we assume that the amount of demand response and flexible generation under management equals the average of the other aggregators.

${ }^{20}$ However, note that not all aggregators provide information on the type of customer they serve.
} 
demand and generation portfolio, however, the aggregators we interviewed cover a major share of marketed demand response.

Table A-2: Prequalified demand response for primary/ secondary/tertiary balancing power and AbLaV (in MW)

\begin{tabular}{lrr}
\hline & $\begin{array}{r}\text { Positive } \\
\text { (load decrease) }\end{array}$ & $\begin{array}{r}\text { Negative } \\
\text { (load increase) }\end{array}$ \\
\hline PRL & 80 & 660 \\
SRL & 540 & 840 \\
MRL & 880 & - \\
AbLaV & 1500 & \\
\hline
\end{tabular}

Source: ÜNB (2018c, 2018d). 
Table A-1: Portfolio size and markets served by German demand response aggregators

\begin{tabular}{|c|c|c|c|c|c|c|c|c|c|}
\hline Name & $\begin{array}{l}\text { Founded in / } \\
\text { headquarter }\end{array}$ & $\begin{array}{r}\text { Portfolio size } \\
\text { Germany (DR and } \\
\text { generation) }\end{array}$ & Industrial customers & $\begin{array}{l}\text { Primary } \\
\text { control }\end{array}$ & $\begin{array}{r}\text { Secondary } \\
\text { control }\end{array}$ & $\begin{array}{l}\text { Tertiary } \\
\text { control }\end{array}$ & AbLaV & Intraday & $\begin{array}{l}\text { Day- } \\
\text { Ahead }\end{array}$ \\
\hline Axpo Deutschland & $\begin{array}{r}2003 \text { / Düsseldorf } \\
\text { und Leipzig }\end{array}$ & - & & $\mathrm{x}$ & $\mathrm{x}$ & $\mathrm{x}$ & & $\mathrm{x}$ & $\mathrm{x}$ \\
\hline BalancePower & 2010 / Munich & - & food industry & & $\mathrm{x}$ & $\mathrm{x}$ & & & \\
\hline BayWa r.e. CLENS & 2008 / Leipzig & 3.300 MW (2019) & $\begin{array}{r}\text { primary industry, food } \\
\text { industry }\end{array}$ & & $\mathrm{x}$ & $\mathrm{x}$ & & $\mathrm{x}$ & $\mathrm{x}$ \\
\hline energy2market & 2009 / Leipzig & - & & $\mathrm{x}$ & $\mathrm{x}$ & $\mathrm{x}$ & $\mathrm{x}$ & $\mathrm{x}$ & $\mathrm{x}$ \\
\hline Entelios & 2010 / Munich & >1.000 MW (2018) & $\begin{array}{l}\text { primary industry, food } \\
\text { industry, aerospace }\end{array}$ & $\mathrm{x}$ & $\mathrm{x}$ & $\mathrm{x}$ & $\mathrm{x}$ & $\mathrm{x}$ & \\
\hline GETEC Energie & 1996 / Hannover & 2.000 MW (2018) & energy intensive industry & $\mathrm{x}$ & $\mathrm{x}$ & $\mathrm{x}$ & & $\mathrm{x}$ & \\
\hline MVV Energie & 1974 / Mannheim & 500 MW (2015) & & & $\mathrm{x}$ & $\mathrm{x}$ & & $\mathrm{x}$ & $\mathrm{x}$ \\
\hline natGAS & 2000 / Potsdam & 950 MW (2018) & $\begin{array}{l}\text { primary industry, food } \\
\text { industry, automotive }\end{array}$ & & $\mathrm{x}$ & $\mathrm{x}$ & & $\mathrm{x}$ & \\
\hline Next Kraftwerke & 2009 / Cologne & 4.909 MW (2018) & different industries & $\mathrm{x}$ & $\mathrm{x}$ & $\mathrm{x}$ & $\mathrm{x}$ & $\mathrm{x}$ & $\mathrm{x}$ \\
\hline Quadra & 2014 / Düsseldorf & - & & & & & & $\mathrm{x}$ & \\
\hline REstore & 2010 / Antwerpen & 2.300 MW (2018) & $\begin{array}{r}\text { primary industry, food } \\
\text { industry }\end{array}$ & $\mathrm{x}$ & planned & planned & $\mathrm{x}$ & & \\
\hline
\end{tabular}

Source: Direct communication with the aggregators and company websites. 